\title{
A way of marketing 3D Web in e-commerce, applying at Car Showrooms period of industrial revolution 4.0
}

\author{
Dr. Pham Minh Dat \\ Thuongmai University \\ Email: minhdat@tmu.edu.vn \\ Dr. Nguyen Thi Hang \\ Faculty of Economic Information System - University of Information and Communication technology, \\ Thai Nguyen, Viet Nam \\ Email: nthang@ictu.edu.vn \\ Associate Professor. Dr. Nguyen Van Huan \\ Faculty of Economic Information System - University of Information and Communication technology, \\ Thai Nguyen, Viet Nam \\ Email:nvhuan@ictu.edu.vn
}

\begin{abstract}
Marketing is one of the important stages, the decisive factor affecting the success of production and business activities of every business. Therefore, marketing is considered to be the first and most important stage in the process of introducing, bringing products to market and branding of businesses, especially in the period when the disease situation is taking place very complicated worldwide. This study provides both qualitative and quantitative results for the following research objectives. Firstly, the study will assess the situation and analyze the appropriateness of marketing models in the current market situation trend. Secondly, the study proposes an approach in building a new type of marketing model, which is 3D web-based marketing applied in e-commerce to support the modeling of enterprise products in the form of Interactive 3D products are similar to real products. Thirdly, testing and evaluating 3D e-commerce web marketing model at Truong Hai Auto Showroom, Thai Nguyen City branch. This study also proposes a number of solutions for the research and deployment of 3D web marketing model application for businesses in the current market situation.
\end{abstract}

Keywords: Industrial Revolution 4.0, Enterprise, E-commerce, 3D web marketing model.

JEL code: M1, M3, J11, O32, F47

\section{INTRODUCTION}

Marketing is one of the important stages, which plays a decisive role in the success of every business. Marketing is considered as the first stage in the process of introducing and bringing products to market. In order to promote effective business activities, most businesses need to propose marketing and promotion solutions to customers about their products.

Marketing is a very common term, which has been particularly interested in research by many production and business managers, including experts or scientists. There have been many publications on both theoretical and practical models, initially making many 
contributions to the social community. Specifically: Marketing is a process, a manufacturer strategy that makes it possible for people to learn about exchanging launched product lines to consumers. Marketing is the process of creating values from customers and close relationships with customers in order to gain value for the benefit of businesses and organizations from the values created (Atul \& Jagdish, 2002; Werner et al., 2004; Chaudhuri, 1999).

In the course of business activities, each business always takes the customer focus as the goal to build, develop and survive. Therefore, the research and propose solutions related to customers are always the top priority of businesses, managers, and business administrators and is one of the key and throughout tasks of the company. Every time there is a new or old product, the access and marketing of old or new customers becomes very important. Businesses always think about how to get customers who know, come, buy, use and be satisfied with the products of production and business units (Chaudhuri, 1999; Oliver, 1999).

One of the factors affecting and also creating success in the business activities of every business is customer marketing. This is considered the first and most important stage in the process of introducing, selling products to the market and branding (Yoo et al., 2000). In order for customers to know the company's products, managers need to develop marketing, marketing and image strategies, and have good relationships with customers. Moreover, enterprises must regularly update and process data to produce accurate and timely reports. The application of information technology will help businesses capture the exact number of customers, help businesses take the initiative in all activities with customers (Pham Thu Huong \& Nguyen Van Thoan, 2009; Ao Thu Hoai, 2010; Nguyen Thi Mai Trang, 2006). From there, businesses can devise marketing, promotion, pricing strategies as well as timely customer service to improve customer satisfaction and customer loyalty about the business (Oliver, 1999).

In the world and in the country, there have been many studies and documents on customer marketing. Thorsten \& Alexander (1998) proposed a customer marketing model through research on the impact of relationship quality on customer loyalty.

Mons et al. (2011) point out the marketing strategy of a company's product development based on the research of marketing strategy and customer interest. Till et al (2014): customer satisfaction about products and services of businesses is considered the key to success, contributing to improving customer marketing. In addition, Papasolomou et al. (2014) propose a customer marketing model based on consumer-oriented marketing public relations. Husnain et al. (2017) studied customer marketing capabilities and assessed customer buying intentions through social media impact.

In fact, most businesses today still apply the traditional marketing methods of introducing products on the spot to customers. There are also businesses marketing via online channels, online, via electronic means, via websites, etc. However, these approaches are considered ineffective in the current market trend, Especially the end of 2019 and from the beginning of 2020, when the world situation is in the stage of the prevention of Covid-19 disease, including Vietnam. Today, more than $50 \%$ of the world's population is at home and socially isolated. Therefore, businesses and regulators have been seeking solutions to market their products 
honestly to customers through online. Therefore, the research businesses proposed online marketing solutions so that the products are honestly and closely simulated with real products. That is considered one of the effective and successful solutions of every business today.

In addition, in today's global integration trend, businesses are focusing on finding new approaches in marketing, promoting, searching and exploiting information, as well as bringing information about our products to our customers. This approach will contribute to promote business activities more effectively. One of the approaches currently being popularized in the trend of integration is to inherit and develop advanced technologies of the Industrial Revolution 4.0, businesses have focused on researching and proposing solution of applying advanced technologies to marketing, promoting its products to customers. In the world, there are many businesses deploying applications for marketing their products to customers based on new technologies such as virtual reality, which are virtual trading platforms for cars and trade markets. 3D electronics, ... These approaches will help businesses to model and simulate products in 3D and be able to interact like reality. This will help customers find and view products that look like real life, attract customers and persuade customers to buy products from businesses.

To promote the advantages of virtual reality technology and develop new marketing models for Vietnamese businesses. The article will study and evaluate the effectiveness of current marketing methods and will provide solutions to deploy and test applications of 3D virtual marketing systems for enterprise's products. Making comparisons with traditional marketing methods, thereby proposing recommendations for businesses in marketing, contributing to increase sales and increase revenue for businesses. The article will pilot a specific case at the Car Showroom with about 124 customers, the customers are on average from 28-35 years old, 60\% of customers have not used cars and the remaining $40 \%$ are currently have and use cars.

\section{METHODS OF BUILDING A 3D E-COMMERCE WEB MARKETING MODEL}

In this section, the paper presents the basic steps for building a customer marketing model based on designing a complete 3D web and an e-commerce trading floor.

\subsection{Propose a simulation process to display products on e-commerce trading floor}

On the basis of an e-commerce platform, the required conditions are the necessary products displayed on the floor, and an e-commerce trading floor which is carried out according to a product display process as follows:

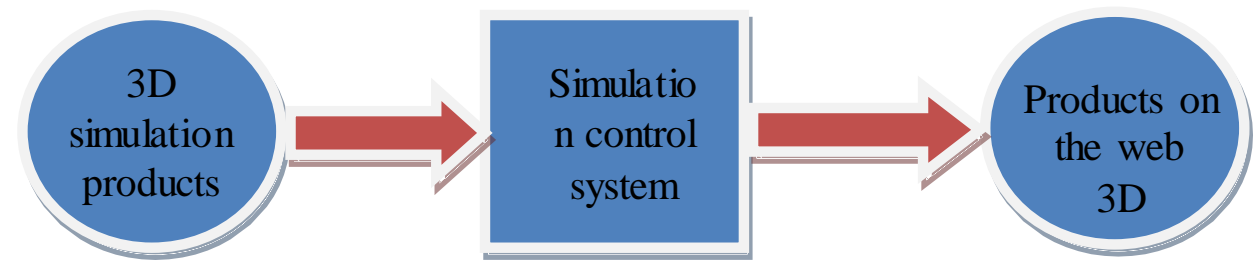

Figure 1: The process of displaying simulation products on the $3 \mathrm{D}$ web 
Source: Author design

The above process consists of 3 steps:

Step 1: Models of goods and products expected to be posted on the 3D web

In this step, the products and goods of the business will be 3D modeled based on 3D modeling tools such as 3Ds Max, Maya, ... and stored in the 3D database.

Step 2: Push the simulation product into the control system.

On the basis of products and goods that have been 3D modeled, this step will be conducted using programming tools such as Visual Studio.net, OpenGL, .. to read and call into the real, 3D control system. show the interaction and control for every detail of products or goods to be true to the real product and goods features.

Step 3: Marketing products

In this step, we will display simulation products on e-commerce $3 \mathrm{D}$ website so that users and customers can view and interact with the products. This is an important and important part of 3D web marketing to customers.

\subsection{Modeling and simulating goods and products posted on the $3 \mathrm{D}$ web}

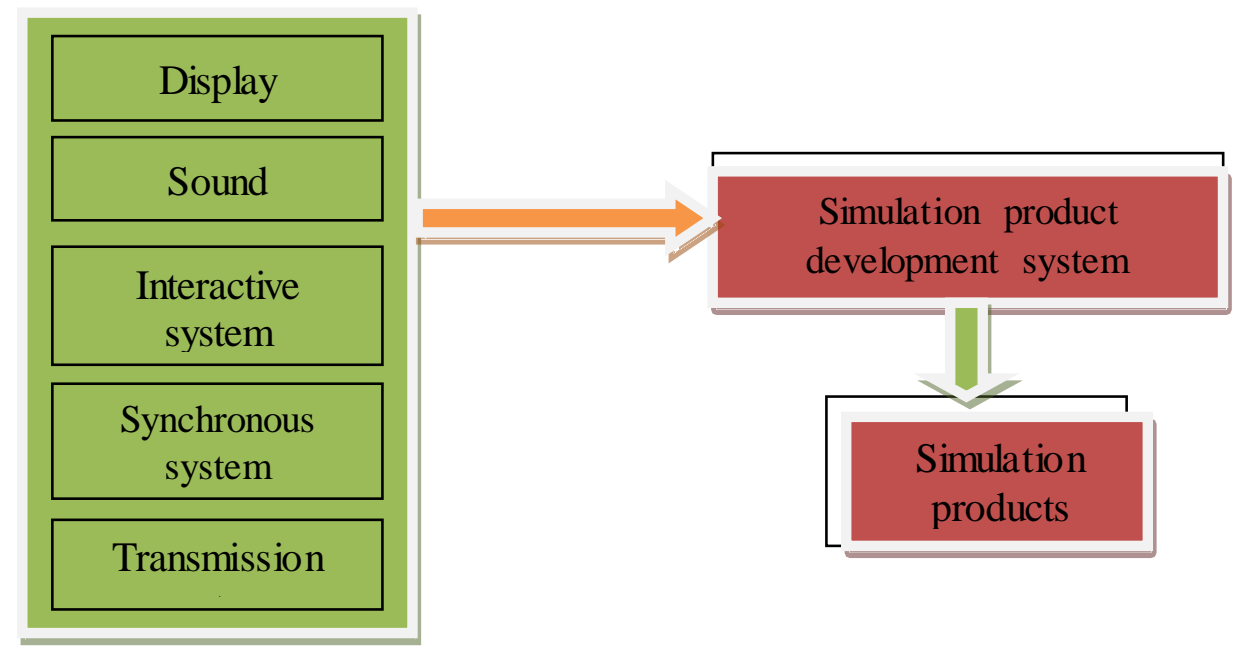

Figure 2: Overview architecture of the system

Source: Author design

Display: Modeling of products and goods must ensure clarity and real quality compared to real images of products and goods.

Audio: used in conjunction with automated marketing to introduce products or goods.

Interactive system: Allows customers to exploit and interact with products and goods on the 3D web model as real. definition.

Synchronous system: The data processing system, sound in accordance with the

Transmission system: Communication system, sound, images to customers when viewing products and goods. 
Simulation product development system: Exploiting tools and languages to support the development, development and testing to finally produce the simulation product.

Simulation products: Is the final result of the simulation stages. Products must reflect the requirements set out during the simulation and must resemble the actual product to be digitized.

\subsection{D web design to support customer marketing}

To design an e-commerce 3D web product, we need to follow these 3 main steps:

Step 1. Collect information for input data

1. Conduct observation, search for information.

2. Information of needed objects in the simulation scene.

3. Size of objects.

4. Collect image data.

5. Proceed to capture and record with Video.

Conduct observation, search for information: Observe to imagine the object to be simulated. From there we have an overview of the content of the functions to be simulated.

Information of needed objects in the simulation scene: To have such information, it is necessary to answer questions such as: dynamic / static objects, tilt, rotate? What is the purpose of object simulation for? By answering all of these questions, we will have all the necessary information in the simulation scene.

Size of objects: Measurement of height and width of simulation objects.

Collect image data and capture images with video: Use high-quality cameras to capture and record at different angles.

Step 2. Develop product simulation data of 3D web system

1. Building simulation data.

2. From image data and video data, it is converted into a format for simulation.

3. Building a data model

4. Based on the size, position and style of the object to build a 3D model.

5 . Building the scenery of the object for the simulation.

6. Build relationships models and bind objects to place on scene.

7. Create levels of detail for scenes and objects.

8. Database of objects in the simulation.

9. Convert 3D models into formats for real-time simulation.

Building simulation data: is a form of image used to "slice" or "paste" on a surface of the object, saved in JPEG, PNG format.

Converting data formats to simulation format: is the image and video formats captured through data collection.

Step 3. Develop the functions of the e-commerce 3D web system and describe the products posted on the 3D web:

Including specific functions:

Updated data: data about products and goods generated during the operation of the system, necessary signals are initially set. 
Model data: The model is collected and processed by tools such as Blender 3D, VRML, ... Then, exported to the format for simulation (.osg, .wrl, ...).

Status of 3D scenes and controls: The states are initially defined at initialization, including the states of the main scene and the merged scenes. The state of the scene is controlled by the control states such as static, moving, rotating, hidden, show, ... All these states will create effects of the simulation scene.

Interactive forms: are the forms of interacting with scenes, which can be interacting through the computer's input system such as keyboards, mice, signals of touch screens.

Multimedia scenario: Including interactive forms, when interacted, how the simulated object will change or react, sound and light effects. This is the operation scenario for the simulated object.

3D scene: After being scripted, the object will be built into a scene in the form of 3D space similar to the real scene and the system displayed on the screen.

Observation: 3D scenes are displayed on the observation screen and the observer perceives, compared to real-world scenes.

Camera update: The viewing position of the scene will be set and controlled by the camera (along the $\mathrm{z}$-axis direction in 3D space). Camera position is like the eye of the observer, can be controlled far and near.

\section{3D WEB CLIENT MARKETING MODEL FOR AUTOMOTIVE PRODUCTS}

In this section, the article will present the steps taken to apply the design process of building an e-commerce 3D web marketing model for automotive products, test evaluation and how to implement the application. fruit.

\section{Describe the requirements of the model:}

The car product marketing system to customers, the product is marketed on the website in 3D. The marketing content must convey a lot of descriptive information about automotive products and its features to customers. And the product must be described to be honest.

When simulating vehicles, it is required to simulate the following minimum functions:

1. Open / close two vehicle doors;

2. Turn the wheel;

3. Open / close two capo covers;

4. View interior interior;

5. Rotate the car in different directions.

\section{Model of automotive products selected for marketing:}

The marketing model is very diverse and diverse, such as: simulation of cars, spaces, houses, ... Here are selected car models.

\section{Solve problems with technologies:}

To create the proposed product, we use some of the following technologies:

1. Modeling tools: Blender, Maya, Photoshop creation tools.

2. Use open source graphics library and 3D data building tools, Visual Studio.net, OpenGL programming environment, ... 
3. Study SceneGraph data types to facilitate interactive programming.

4. Programming to convert software to $3 \mathrm{D}$ format from modeling tools to a specific SceneGraph format for real-time graphic display.

5. Building program modules, separating and displaying multi-channel graphic scenes, enhancing the reality of scenes under the effect of specialized glasses. graphic quality.

6. Lets display the model when a multi-layered (16-layer) image overlay increases the

7. Develop algorithms that allow creating shadows in real-time graphics.

8. Create the process of building 3D data.

9. Research browser architecture and programmatically put products on the $3 \mathrm{D}$ web.

\section{Describe and analyze database design requirements:}

Let's say the automaker wants to market its newly produced car product to customers. A form of marketing is a product that is modeled as a three-dimensional space and posted on the company's website.

Table 1: Describe in detail the features the company requires when building a product

\begin{tabular}{|c|c|c|c|}
\hline Subject & Status & Action & Note \\
\hline CAR DOOR & $\begin{array}{l}\text { Open / } \\
\text { close }\end{array}$ & $\begin{array}{l}\text { CLeft mouse } \\
\text { click }\end{array}$ & $\begin{array}{l}\text { Left click once, the corresponding car } \\
\text { door slowly open / close. Click the } \\
\text { next time, then stop. Double tap then } \\
\text { immed iately close / open. }\end{array}$ \\
\hline WHEEL & $\begin{array}{l}\text { Spin around } \\
\text { its axis }\end{array}$ & $\begin{array}{l}\text { Left mouse } \\
\text { click }\end{array}$ & $\begin{array}{l}\text { Left click, the wheel rotates / stops } \\
\text { around the axis, then the next stop / } \\
\text { spin. }\end{array}$ \\
\hline CAPO CAP & $\begin{array}{l}\text { Open / } \\
\text { close }\end{array}$ & $\begin{array}{l}\text { Left mouse } \\
\text { click }\end{array}$ & Left mouse click \\
\hline FURNITURE & Display & Click & $\begin{array}{l}\text { Scroll the mouse or use the keys to } \\
\text { tour the interior. }\end{array}$ \\
\hline VIEWS & Current & $\begin{array}{l}\text { Click mouse / } \\
\text { key }\end{array}$ & $\begin{array}{l}\text { Rotate the mouse to see in different } \\
\text { directions. }\end{array}$ \\
\hline
\end{tabular}

Source: Interpretation of the author

\section{Build 3D model database:}

Collecting image data: The image of the vehicle is taken with high quality camera to make data.

3D image modeling: After collecting image data, it will retrieve mapping data from the corresponding image by Blender data processing software tool. This data is used to rebuild the vehicle model as the original model.

Data export: After taking overview data (including refinement), that data will be exported to the corresponding parts to build the data structure.

When finished covering the parts, all the data will be packaged into a file with the extension .flt, from this packet will be converted into a data package with the extension in 
Programmers' needs are specific to the programmer's organization. Here, the data will be exported to a file with the extension .w2g.

This data package will be used to make programming data with basic tasks such as texture coating, lighting processing, shadow effects, automotive functions.

Geometric objects in a data tree:

- Car: The whole car body

- Body: Car body

- Wheel: Wheel

- Capo: Car covers

- Door: Car door

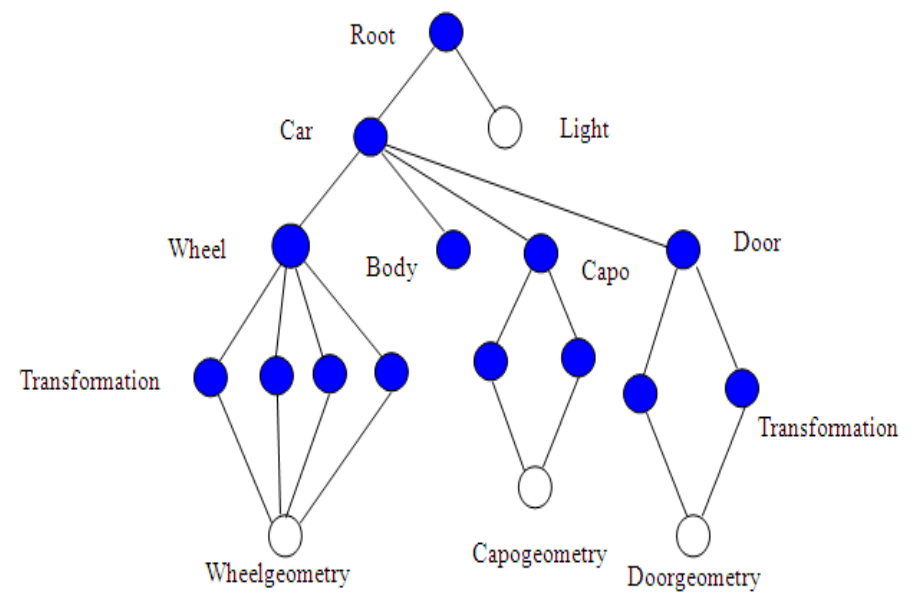

Figure 3: Model of Geometry data tree of a car

\section{Marketing tree model and 3D web model:}

Source: Interpretation of the author

This section will present the results of the 3D web marketing model, through which users, customers can exploit and view the company's automotive products based on the model and can view. Details, components, parts of cars as in reality.

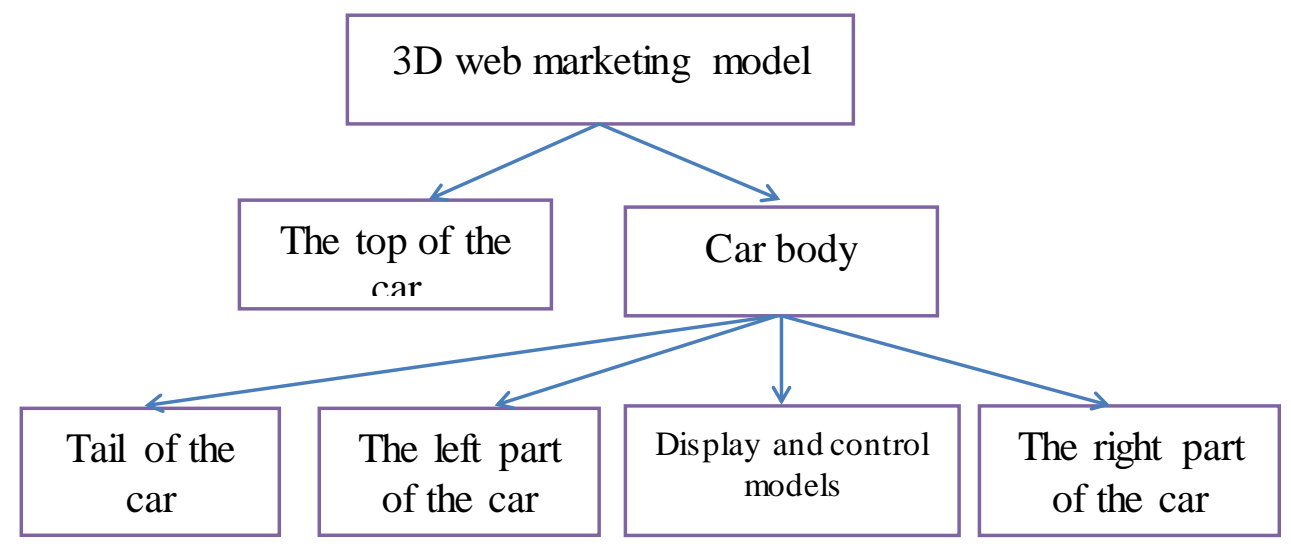

Figure 4: Product model web marketing 3D

Source: Interpretation of the author 
With the image above, customers can display and interact with $3 \mathrm{D}$ models such as reality, open doors, interactively control, view interior details, open capo covers, etc. This will help customers can see and select which car products are suitable for their design and interior, features through 3D web marketing. Instead of going to the place to see the features, customers can observe the interior of automotive products in the most honest way.

\section{Evaluate the effectiveness of $3 \mathrm{D}$ web marketing model:}

To evaluate the effectiveness of the $3 \mathrm{D}$ e-commerce web marketing model, the authors make a comparison between customer marketing model based on 3D web and traditional web.

The method to evaluate the effectiveness of the $3 \mathrm{D}$ web marketing model used is the survey survey method. The brief steps are as follows:

Step 1: Analyze and design the questionnaire in the questionnaire

Step 2: Consult an expert and adjust the questionnaire in the questionnaire

Step 3: Select the customer sample

Step 4: Organize the distribution of online survey forms

Step 5: Summarize, process and evaluate survey results

Using online survey method: below are the results of surveys and surveys of 124 customers in Vietnam, customers whose average age is from 28-35 years old, of which 60\% customers do not have a car and the remaining $40 \%$ currently own and use a car. The questionnaire was designed primarily with 9 main criteria in Table 2 in addition to other subcriteria.

Table 2: Comparison results between two marketing models 3D and 2D

\begin{tabular}{clcc}
\hline Sort & \multicolumn{1}{c}{ Criteria } & $\begin{array}{c}\text { 3D Web } \\
\text { marketing } \\
\text { model }\end{array}$ & $\begin{array}{c}\text { Traditional Web } \\
\text { marketing model } \\
\text { (2D) }\end{array}$ \\
\hline 1 & Full information & $89 \%$ & $11 \%$ \\
2 & Easy to exploit information about cars & $92 \%$ & $8 \%$ \\
3 & $\begin{array}{l}\text { Highly recognizable automobile } \\
\text { models }\end{array}$ & $100 \%$ & $0 \%$ \\
4 & Realistic car models near reality & $95 \%$ & $5 \%$ \\
5 & Easy to view car parts & $97 \%$ & $3 \%$ \\
6 & Easy to see interior is accurate & Dễ & Khó \\
7 & Can see the machine, roar & See every angle & Can't watch it \\
8 & You can sit in a car and test drive it & Viewable & Cannot watch \\
9 & Display and observe cars in any angle & Viewable & Cannot watch \\
\hline
\end{tabular}

Source: Processing results and author's calculations

With a 3D web-based customer marketing model, it will contribute to better efficiency for the business, bringing the product closer to the needs of customers.

For 3D web marketing model: the products of the enterprise are designed to display as an interactive 3D model, customers can display and interact with the real product. At the same 
time, they can observe the goods displayed from different angles. This will contribute to attract and attract customers to the products of the business to further stimulate the curiosity of the company's goods and products. While the 3D web marketing model still ensures the same features as traditional web and conventional marketing models. With a 3D web-based customer marketing model, customers can display cars in many different angles and can interact with cars almost in real-time view, customers can open Each door, open the lid to see the machine, the interior, ...

Whereas, for a traditional marketing model such as organizing events so that customers can come to see the products, it costs money. If using ordinary web, customers can only read words, view pictures of products like cars, then customers can not view and interact like 3D models. On the other hand, the image of the product is not viewed as the same as the real product. With the conventional web, we take pictures of each $2 \mathrm{D}$ car part posted on the web.

This method is applicable to many products that need to be marketed on the web and this method is easy to implement because it only requires editing photos and posting them on the website. But if a car, in order to get a lot of information to customers, you need to take pictures of a lot of parts. This job will make the website rough, large capacity makes the web slow, costly for data storage, customers have to see each part through photos. This will be boring for customers, and especially do not convey the content you want to experience with the product of the customer.

Comment: Thus, the marketing model of customers based on 3D web platform will contribute to creating benefits for both businesses and customers, specifically:

On the business side: Marketing of products and goods that are honestly similar to those in reality. This will be beneficial in attracting, attracting and engaging customers in viewing, researching and leading to decisions about shops, businesses and the decision to choose and buy products and goods. Contributing to boosting sales and thereby increasing sales and profits for businesses. From there, create trust for customers. Businesses can market all kinds of products, goods anytime, anywhere and every time to customers. Whereas, with old and traditional marketing models, customers who want to see and research products and goods honestly with real models must have time and hours of business. At that time, customers must arrange a time to see and learn about products and goods. This will inconvenience customers.

On the customer side: It is possible to search, view and observe products and goods honestly and with high practicality of products and goods like in real life. Create trust for customers so customers can observe and buy products and goods. In particular, the fact that customers can search and research all kinds of products and goods through 3D web-based marketing system will contribute to bringing convenience to customers. Customers will save money, travel time and can search and view the goods and products of the business honestly anytime, anywhere before deciding to select, come and buy products, goods. 


\section{CONCLUSION}

Marketing is an important and indispensable step in the production and business activities of each business. Marketing is considered to be a decisive factor in driving sales of each business. Moreover, it will contribute to boosting revenue and profits for businesses.

The paper focused on researching and proposing solutions to build customer marketing models during the 4.0 industrial revolution based on 3D web platform and pilot application of 3D web marketing models with 124 customers. Survey results from customers with an average age of 28-35 years old, of which $60 \%$ of customers do not have a car and the remaining $40 \%$ currently have and use cars of Truong Hai Auto Company Vietnam. The results showed that the proposed marketing model was evaluated by customers as good and highly responsive. With 3D web marketing model, customers can display, observe and interact to control the product model of their products. This helps customers who are far from Showrooms, including nearby, can visit the showrooms first to learn about products and goods before deciding to go to the showrooms to see and buy the product. goods that you like.

\section{References}

[1] Atul, P.\& Jagdish N. S.(2002), 'Customer Relationship Management: Emerging Practice, Process, and Discipline', Journal of Economic and Social Research, 3(2), 1-34.

[2] Ao Thu Hoai (2010), 'Online Marketing', Publisher of Posts and Telecommunications Institute of Technology.

[3] Alawi, H. (1986). Saudi Arabia: making sense of self-service. International Marketing

Review, Vol. 3 No. 1, Spring, pp. 21-38.

[4] Aylott, R. and Mitchell, V. (1999). An exploratory study of grocery shopping stressors.

[5] Chaudhuri. (1999), 'The Effects of Brand Attitudes and Brand Loyalty on Brand Performance', European Advances in Consumer Research, 4.

[6] Fox E., Montgomery, A. and Lodish, L. (2004), “Consumer shopping and spending across retail formats", Journal of Business, Vol. 77 No. 2, pp. 25-60.

[7] G. Thirunarayanan, Application of Hammett equation on IR and NMR spectral data of (5bromothiophen-2-yl) (3-(4-methoxyphenyl)bicyclo[2.2.1] hept-5-en-2-yl)methanones. World Scientific News 53(3) (2016) 138-156.

[8] Husnain, M.\& Toor, A. (2017), 'The Impact of Social Network Marketing on Consumer Purchase Intention in Pakistan: Consumer Engagement as a Mediator', Asian Journal of Business and Accounting, 10 (1), 167-199.

[9] Jacoby, C.(1978), 'Brand Loyalty Measurement and Management', New York: Wiley.

[10] Mons, F.S., Sven, A.H., Kjell, G. \& Trond, H.(2011), 'Marketing strategy and customer involvement in product development', European Journal of Marketing, 45(4),513-530 . DOI: $10.1108 / 03090561111111316$. 
[11] Ndubisi, N.(2007), 'Relationship marketing and customer loyalty', Marketing Interlligent \& Planning, 25(1), 98-106.

[12] Nguyen Thi Mai Trang (2006), 'Service quality, satisfaction, and loyalty of supermarket customers in Ho Chi Minh City Journal of Science and Technology Development, Vol. 9, No. 10.

[13] Papasolomou, I., Thrassou, A. \& Vrontis D. (2014), 'Marketing Public Relations: A Consumer-focused Strategic Perspective', Journal of Customer Behaviour, 13(1), 5-24.

[14] Pham Thu Huong and Nguyen Van Thoan (2009), 'Application of Electronic Marketing in Business', Science and Technology Publishing House.

[15] Oliver. (1999). 'Whence consumer loyalty', Journal of Marketing Research, 63, 33- 44.

[16] Till, H., Benjamin, Q., Jan, W. \& Mario, R.(2014), 'Footprints in the Sands of Time: A Comparative Analysis of the Effectiveness of Customer Satisfaction and CustomerCompany Identification over Time', Journal of Marketing, 78, 78-102.

[17] Thorsten, H.T.\& Alexander, K.(1998), 'The impact of customer satisfaction and relationship quality on customer retention: A critical reassessment and model development', Psychology \& Marketing, 14, 737-764.

[18] T. Borowski, Modifications of natural rubber (Hevea brasiliensis): production, application and comparison. World Scientific News 7 (2015) 20-52.

[19] Werner, R., Manfred, K.\& Wayned, H.(2004), 'The Customer Relationship Management Process: Its Measurement and Impact on Performance', Journal of Marketing Research, Vol. XLI (August 2004), 293-305.

[20] Yoo \& ctg. (2000), 'An examination of selected Marketing mix elements and brand equity', Journal of the Academy of Marketing Science, 195-211. 